\title{
The interface between cholinergic pathways and the immune system and its relevance to arthritis
}

\author{
Robin M McAllen ${ }^{1 *}$, Andrew D Cook ${ }^{2}$, Hsu Wei Khiew ${ }^{2}$, Davide Martelli ${ }^{1}$ and John A Hamilton ${ }^{2+}$
}

\begin{abstract}
The nervous and immune systems are likely to be interacting in arthritis, with the possible involvement of both neural and non-neural cholinergic transmission. Centrally acting muscarinic agonists, electrical stimulation of the vagus and treatment with nicotinic receptor agonists can all act systemically to reduce inflammation, although the responsible pathways are incompletely understood. While this 'cholinergic anti-inflammatory pathway' is widely viewed as a significant pathophysiological mechanism controlling inflammation, the evidence supporting this view is critically reviewed and considered inconclusive; an alternative pathway via sympathetic nerves is implicated. This review also discusses how cholinergic pathways, both neural and non-neural, may impact on inflammation and specifically arthritis. Nicotinic agonists have been reported to reduce the incidence and severity of murine arthritis, albeit an observation we could not confirm, and clinical studies in rheumatoid arthritis have been proposed and/or are underway. While the therapeutic potential of nicotinic agonists and vagal stimulation is clear, we suggest that the 'cholinergic anti-inflammatory pathway' should not be uncritically embraced as a significant factor in the pathogenesis of rheumatoid arthritis.
\end{abstract}

\section{Introduction}

Nervous and immune system interactions are likely to be occurring in arthritis, as exemplified by the observation that hemiplegic patients do not develop psoriatic arthritis on their denervated side [1]. In this review we will try to identify relevant cholinergic pathways in the physiological and pathophysiological sense - those that are actually used by the body in vivo. Recently it has become increasingly apparent that, as well as responding to transmitters released by autonomic nerves, cells of the immune system may express and intercommunicate by these same transmitters [2,3]. The different types of cholinergic pathway are shown in Figure 1. These are (i) central nervous, (ii) preganglionic and postganglionic parasympathetic, (iii) preganglionic and postganglionic sympathetic, (iv) somatic motoneuron and (v) non-neural (cell-cell interaction). All somatic motoneurons, all preganglionic neurons and most postganglionic parasympathetic neurons are cholinergic. Only a minority of central and sympathetic postganglionic neurons are cholinergic.

\footnotetext{
* Correspondence: rmca@florey.edu.au

${ }^{\dagger}$ Equal contributors

'Florey Institute of Neuroscience and Mental Health, University of Melbourne, Parkville, Victoria 3010, Australia

Full list of author information is available at the end of the article
}

The latter supply targets such as the sweat glands and are unlikely to be directly involved in modulating immune function [4]. Vagal afferent neurons are not included since they are generally not cholinergic (see below).

The cholinergic neurons that influence immune function may do so directly by the actions of synaptically released acetylcholine on immune cells, or indirectly by synaptically exciting other neurons with the same or different transmitters (for example, noradrenaline). They do not directly innervate joints. The immune mechanisms to be considered will focus on the control of inflammation and, where specific information exists, its relevance to arthritis. We will then review the pharmacological actions of cholinergic agonists on monocytes/macrophages and report new findings on how they affect murine collageninduced arthritis.

\section{Central neural cholinergic pathways}

Around the turn of the century Borovikova and colleagues, working in the Tracey laboratory, showed that an anti-inflammatory drug, CNI-1493, was effective in suppressing both local inflammation (carrageenan-induced paw oedema) and systemic inflammation (hypotension and the inflammatory cytokine response to intravenous treatment with lipopolysaccharide (LPS)) in anaesthetised 

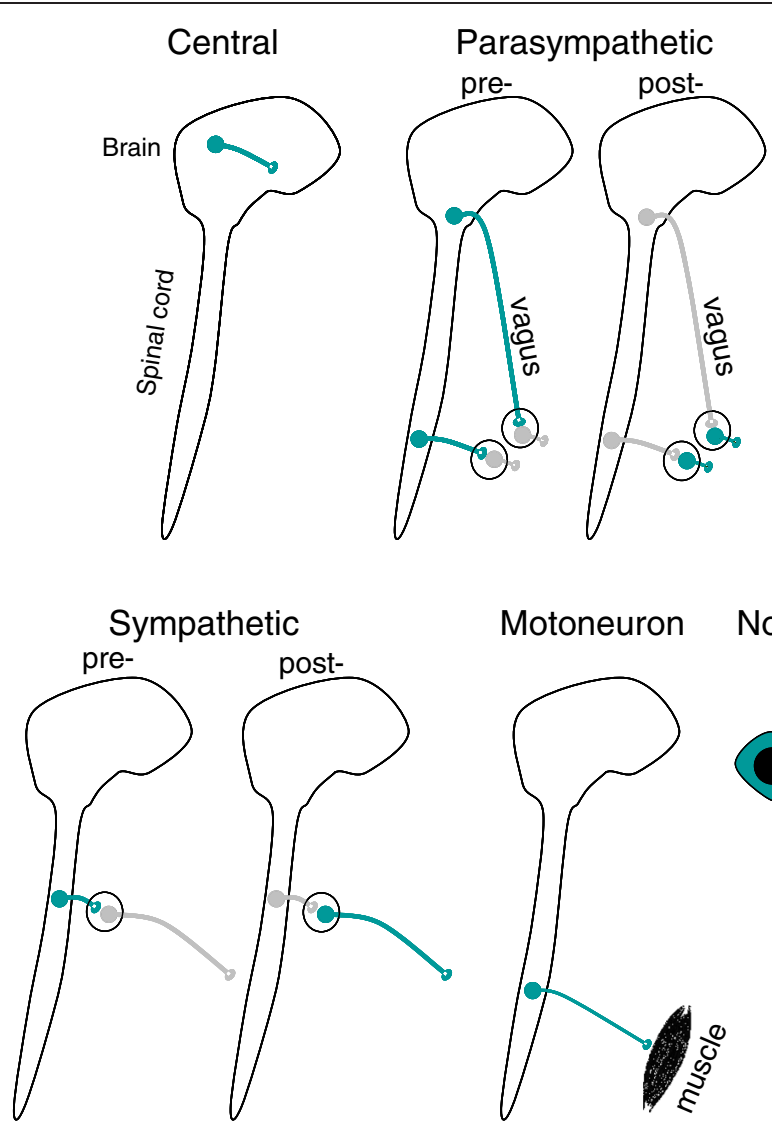

Motoneuron

Non-neural (e.g.)
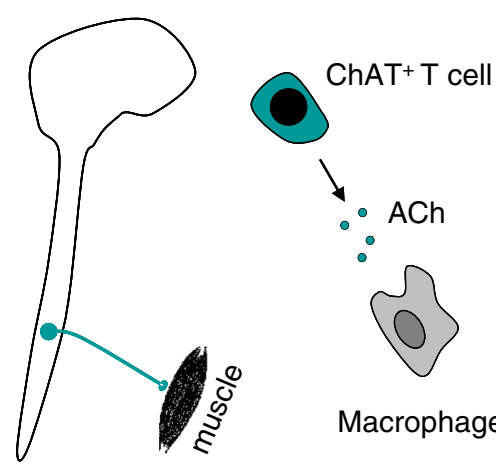

Macrophage

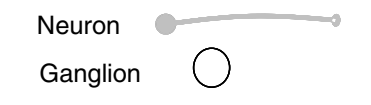

Figure 1 Schematic summary of the types of cholinergic pathway. The following cholinergic pathways are highlighted in green in successive diagrams: (i) central nervous, (ii) preganglionic and postganglionic parasympathetic (cranial and sacral), (iii) preganglionic and postganglionic sympathetic, (iv) somatic motoneuron and (v) non-neural (showing an example of a cholinergic cell-cell interaction). All somatic motoneurons, all sympathetic and parasympathetic preganglionic neurons and most parasympathetic postganglionic neurons are cholinergic; the remainder are subsets. $\mathrm{ChAT}^{+}=$choline acetyl transferase-positive; that is, acetylcholine (ACh) expressing.

rodents $[5,6]$ - the strength of a systemic inflammatory response to a stimulus such as LPS is often measured by the levels of the pro-inflammatory cytokine, tumour necrosis factor (TNF) [7]. These workers found that CNI-1493 was many times more potent in suppressing inflammation when given into the cerebral ventricles than when given intravenously, showing that its site of action was in the central nervous system [5]. Later, it was found to act via central muscarinic receptors, and that other muscarinic agonists with central neural actions had similar antiinflammatory effects [8]. Furthermore, treatment with the centrally acting cholinesterase inhibitor, galantamine, was found to suppress acute systemic inflammation [9]. This last finding suggests that central cholinergic neurons (Figure 1) tonically release acetylcholine close to the muscarinic receptors that drive the anti-inflammatory action.
The output pathway stimulated by these central muscarinic actions was found to run in the vagus nerves (discussed below). The anti-inflammatory action of these muscarinic agonists was blocked by centrally acting muscarinic antagonists but not by atropine methyl nitrate, which does not cross the blood-brain barrier [8]. These observations are in line with those of others who concluded that central but not peripheral muscarinic receptors have an anti-inflammatory action [10].

Muscarinic receptors in the spinal cord have also been shown to exert anti-inflammatory actions. Yoon and colleagues [11] found that intrathecal injection of a muscarinic M2 receptor agonist suppressed peripheral inflammation in the zymosan-treated air pouch model in mice. In this case, however, the anti-inflammatory action was mediated by sympathetic nerves to the adrenal medulla and the release of adrenal catecholamines [12]. 


\section{The 'cholinergic anti-inflammatory pathway' and the vagus}

Following their demonstration that the anti-inflammatory actions of CNI-1493 were mediated by the vagus nerves, Tracey's group and subsequently others have shown that electrical stimulation of the peripheral end of either the left or the right cut vagus has strong systemic antiinflammatory actions $[3,5,13,14]$. In most cases the inflammatory cytokine response to systemic LPS treatment has been measured in anaesthetised rodents, and this is reduced substantially by vagal stimulation. These and other relevant actions of vagal stimulation are well reviewed elsewhere [15].

Surprisingly for an action mediated presumptively by postganglionic parasympathetic nerves (Figure 1), the anti-inflammatory effects of vagal stimulation are not blocked by muscarinic antagonists such as atropine methyl nitrate [8], although they are blocked by antagonists of $\beta_{2}$ adrenoreceptors and are absent in mice lacking those receptors [16]. Nicotinic acetylcholine receptors (nAChRs) containing the $\alpha 7$ subunit $(\alpha 7 \mathrm{nAChR})$ were found to be essential for its action, because the effect was absent in mice lacking this subunit [17]. However, the site of those essential nicotinic receptors is uncertain (discussed in more detail in [18]). $\alpha 7 \mathrm{nAChR}$ is predominantly expressed in neuronal tissues but also in several non-neuronal cell types such as immune cells (for example, monocytes, macrophages, lymphocytes), epithelial cells and adipocytes [19] (Figure 1). This vagally mediated anti-inflammatory action has been termed the 'cholinergic anti-inflammatory pathway' $[7,15]$.

As discussed elsewhere [18], the pathway from the vagus to its anti-inflammatory action is complex and incompletely understood. It involves the spleen [20] and the splenic nerves [14], but the proposal [15] that it is mediated by a direct synaptic connection from the vagus to the splenic nerves (which are sympathetic) has been refuted [21]. A non-neural link (Figure 1), possibly mediated by acetylcholine-secreting $\mathrm{T}$ lymphocytes [3], seems to form an essential part of the pathway [18]. B lymphocytes can also produce acetylcholine, which is reported to control local neutrophil recruitment to the peritoneum in response to endotoxin [22]. Further, stimulation of the vagus has been found also to inhibit leukocyte migration in another site that it does not innervate - the carrageenan air pouch model of inflammation [23].

\section{The inflammatory reflex}

The concept of an inflammatory reflex, in which the central nervous system responds to inflammatory stimuli and acts to limit peripheral or systemic inflammation, was clearly formulated by Tracey [7]. In parallel with this neural reflex, but slower to act, is the release of glucocorticoids by the hypothalamic-pituitary-adrenal axis
$[24,25]$. These two mechanisms are seen as early regulators by which the body acts to moderate the strength of the inflammatory response to infection or injury.

It has been stated in a number of articles that the 'cholinergic anti-inflammatory pathway' constitutes the efferent neural arm of the inflammatory reflex $[7,15]$. The critical test for this idea is that when the proposed inhibitory pathway is disconnected (that is, by cutting the vagi to interrupt parasympathetic preganglionic transmission; Figure 1) this should exacerbate the strength of the inflammatory response to immune challenge. In the original paper describing the vagal pathway, this appeared to happen: Borovikova and colleagues [6] found that cutting the vagi in anaesthetised rats caused a $40 \%$ increase in their inflammatory response (measured by plasma levels of TNF) to a high dose of intravenous LPS. However, later studies from the same and other laboratories have failed to replicate this finding [26-29]. The possible reasons are discussed elsewhere [18]. We recently reinvestigated this question using the same paradigm - measuring the plasma TNF response to intravenous LPS in anaesthetised rats and found that cutting the vagi had no effect on this measure of inflammation [28]. By contrast, sectioning of the splanchnic sympathetic nerves increased the TNF response to LPS five-fold. We concluded that the efferent arm of the inflammatory reflex runs not in the vagi but in the splanchnic sympathetic nerves [28]. This is in line with a substantial body of literature that implicates sympathetic nerves in the control of systemic inflammation [30-32]. Critically, however, our findings indicate that the cholinergic anti-inflammatory pathway' in the vagus is not activated endogenously by systemic inflammation, only by exogenous pharmacological or electrical means. This has implications for its potential role in inflammatory conditions such as arthritis (see below).

\section{Where vagotomy does affect inflammation}

In contrast to the case with systemic inflammation, there is good evidence for the involvement of the vagus in modulating inflammation of the gut and abdominal viscera. For example, prior sectioning of the left cervical vagus has been shown to enhance the blood levels of inflammatory cytokines measured in mice 6 hours after the induction of septic peritonitis [33]. Unilateral vagotomy also worsens the severity of cerulean-induced pancreatitis and raises the levels of the associated circulating proinflammatory cytokines over a time course of days [34]. These and related findings on the vagal modulation of intestinal inflammation are ably reviewed elsewhere [35].

In keeping with the idea that there is some abdominal 'local sign' in the vagal anti-inflammatory influence, mild inflammation was detected in the lungs of the same mice that were given pancreatitis, yet the lung inflammation was unaffected by vagotomy [34]. Furthermore, in experiments 
where the lungs of rats were directly inflamed by exposure to diesel soot, vagotomy was actually found to reduce the lung inflammatory response, suggesting a vagal pro-inflammatory action in this tissue [36]. This proinflammatory action was blocked by atropine [36].

What remains unclear from these findings, however, is whether the protective actions of the vagus are mediated by parasympathetic efferent fibres (as in Figure 1) - that is, the 'cholinergic anti-inflammatory pathway' - or by vagal afferent fibres (or perhaps both). Some 80 to 90\% of the nerve fibres that run in each vagus are not parasympathetic but are visceral afferents [37]. Critically, these are generally not cholinergic. They can have antiinflammatory actions, as shown by the following examples. In animals given colitis (usually induced experimentally by trinitrobenzenesulfonic acid), vagotomy worsens the severity of the disease [38]. Selective destruction of vagal afferents with capsaicin treatment (which blocks traffic in a subset of afferent fibres while sparing autonomic efferents [39]) also worsens disease severity [40] and increases mortality [41], suggesting that vagal afferents normally have an anti-inflammatory action. In rats subjected to haemorrhagic shock or acute haemolysis, Luyer and colleagues $[42,43]$ have demonstrated a dramatic protective effect of a high-fat diet. In haemorrhagic shock, the levels of proinflammatory cytokines, such as TNF and interleukin-6, were dramatically lower in the fat-fed animals and their intestinal barrier integrity was preserved [43]. This protection disappeared if the vagi were cut or the animals were given antagonists to cholecystokinin [42], which is released by lipid in the intestine and stimulates vagal afferents [44]. A high-fat diet was also found to reduce the damaging effect of haemolysed blood on kidney, liver and intestinal function. This protection also depended on the vagi and cholecystokinin receptors [45], indicating that a reflex mediated by vagal afferent fibres was responsible. In all these cases the protective effects of vagal afferents were blocked by systemic administration of nicotinic antagonists such as chlorisondamine or hexamethonium. These data indicate that the efferent pathway of the protective reflex triggered by vagal afferents is probably autonomic, but do not distinguish whether it is sympathetic or parasympathetic.

In summary, in contrast to the case in acute systemic inflammation, the vagi mediate an inhibitory action on abdominal inflammation. It is unclear, however, whether any of this protective action is mediated by vagal efferent fibres of the 'cholinergic anti-inflammatory pathway'. There is strong evidence that vagal afferent fibres are involved, but there is no evidence yet proving that the reflex motor pathway is vagal rather than sympathetic. Indeed in the case of another reflex response to abdominal inflammation - gastroparesis following intestinal manipulation - it has been shown that the afferent pathway is vagal but the efferent pathway is sympathetic [46].

\section{The 'cholinergic anti-inflammatory pathway' and arthritis}

The vagus nerve does not directly innervate the joints, so any action that it may have on arthritis must be indirect. Nevertheless, could a loss of control by the 'cholinergic anti-inflammatory pathway' play a role in maintaining arthritis? This hypothesis [47] was investigated in mice by van Maanen and colleagues [48], who found that unilateral cervical vagotomy caused only a non-significant trend to worsen the disease. Wu and co-workers [49] recently confirmed that unilateral vagotomy had no significant effect. On the other hand, collagen-induced arthritis was found to be exacerbated in mice lacking $\alpha 7 \mathrm{nAChR}$ [50], suggesting that nicotinic receptors independent of the vagus could be relevant (discussed below). In humans, a large case-control study on data from nearly 200,000 patients on the Swedish inpatient register found that surgical vagotomy caused no excess risk of developing rheumatoid arthritis (RA) [51], although it did not investigate whether vagotomy affected disease severity.

On the other hand, several correlation studies have investigated a link between parasympathetic nerve activity to the heart (cardiac vagal tone) and inferred activity in the 'cholinergic anti-inflammatory pathway'. High frequency heart rate variability (HF-HRV) and beat-to-beat variability of cardiac interval both measure respiratory sinus arrhythmia, which is an index of cardiac vagal tone. It is commonly used in measures of 'sympathovagal balance', a major determinant of health. Reduced heart rate variability has been described in RA and systemic lupus erythematosus patients [52]. In addition, heart rate variability correlated with RA disease severity [47] and was suppressed compared with that in normal controls. This is in line with evidence that HF-HRV is reduced in other inflammatory conditions and correlates inversely with inflammatory markers such as $C$ reactive protein on a population basis [53].

To suggest that cardiac vagal tone reflects tone in the vagal fibres of the 'cholinergic anti-inflammatory pathway' [47] is a bold hypothesis, given that most evidence indicates that parasympathetic tone is organ-specific [4]. Bradycardia and penile erection, for example, are both parasympathetic nerve actions: trained athletes have strong cardiac parasympathetic tone and a slow resting heart rate but they do not generally walk around with a permanent erection! In the case of acute systemic inflammation, our evidence does not support the hypothesis. Cutting the vagi in LPS-treated rats revealed significant cardiac vagal tone (heart rate increased by 50 beats/ minute) but no functional tone in the 'cholinergic anti-inflammatory pathway' (inflammation was not 
exacerbated) [28]. Whether cardiac vagal tone turns out to be a surrogate measure of tone in the 'cholinergic antiinflammatory pathway' over the longer term remains to be proven. On the other hand it is well established that cardiac vagal tone (measured by HF-HRV) is directly suppressed by peripheral inflammatory stimuli [54], which act via the brain to alter autonomic function [55]. The raised pulse rate that accompanies fever is familiar to us all. Therefore, reduced cardiac vagal tone (HF-HRV) is a predictable consequence of peripheral inflammatory processes, and this would provide the most parsimonious explanation for why it varies inversely with inflammatory markers. Any causative relation remains unproven.

\section{Vagal stimulation in arthritis}

Even if the endogenous role of vagal transmission in the aetiology of arthritis is uncertain, could there be a therapeutic role for vagal stimulation to relieve arthritis? It is known that vagal stimulation can suppress limb inflammation (carrageenan-evoked paw oedema) in the acute setting [5]. In the chronic setting, Zhang and co-workers [56] reported that a novel technique, 'vagus nerve suspension', resulted in a modest but significant amelioration of collagen-induced arthritis in rats over 2 to 5 weeks. The authors suggested that the technique caused chronic vagal stimulation, perhaps by a combination of mechanical irritation and local inflammation [56]. Without further investigation, however, it is unclear to what extent the effect of suspension on the vagus might be damage rather than stimulation, or what its mode of action on arthritis might be. Very recently, however, Levine and colleagues [57] showed convincingly that electrical stimulation of the left cervical vagus with chronically implanted cuff electrodes substantially reduced ankle swelling and histological measures of arthritis in rats with collagen-induced arthritis. The therapeutic effect was well developed within a week of stimulation treatment which, strikingly, was given for only 60 seconds per day [57]. Necessarily, both afferent and efferent vagal nerve fibres remained intact. Action potentials conduct in both directions so, besides confirming the finding, it is important for future studies to determine whether the therapeutic benefit is due to stimulating parasympathetic efferent fibres, visceral afferent fibres or both.

\section{Sympathetic preganglionic neurons in inflammation and arthritis}

The evidence for a role of preganglionic sympathetic neurons (all of which are cholinergic; Figure 1) in modulating immune responses is nearly all indirect. One exception is our recent demonstration of the strong anti-inflammatory action mediated by the preganglionic sympathetic neurons of the splanchnic nerves in endotoxemic rats [28]. Another is the demonstration that the anti-inflammatory action of bee venom is mediated by preganglionic neurons to the adrenal medulla in mice [12]. By contrast, the evidence for a strong immunomodulatory role of sympathetic postganglionic neurons (most of which are noradrenergic) is overwhelming. This has been well reviewed elsewhere [30,32].

In the context of arthritis, several technical factors prevent us directly inferring the roles of preganglionic sympathetic nerves from those of postganglionic sympathetic nerves. First, not all the actions of postganglionic sympathetic nerves depend on preganglionic neural inputs. Janig and Green [58] have recently reviewed their studies on bradykinin-evoked plasma extravasation in the rat knee joint, which clearly showed that this inflammatory response depended in large measure on the presence of sympathetic nerve terminals in the joint but not on their neural activity or their preganglionic inputs. They postulated that this was due to ongoing, nonsynaptic release from the terminals of inflammatory mediators such as prostaglandins [58]. Second, the standard approach used to investigate the immunomodulatory role of sympathetic nerves is to destroy their terminals with the toxin, 6-hydroxydopamine (6-OHDA). Unfortunately this also destroys catecholaminergic immune cells, which play an increasingly dominant role over the time course of arthritis as local noradrenergic terminals withdraw [59]; therefore, interpretation of its effects is complicated. Third, chemical sympathectomy with systemic 6-OHDA in the presymptomatic phase of arthritis lessens disease severity but this treatment during the established phase worsens the disease [60], suggesting a bimodal action. Fourth, local and systemic sympathetic nerves may have opposing actions. In rats given adjuvant-induced arthritis, Lorton and colleagues [61,62] injected 6-OHDA into the lymph nodes that drain the hindlimbs, which sympathectomised internal organs, including the spleen, but preserved the sympathetic innervation in the limbs. This worsened hindlimb arthritis, even when given presymptomatically. By contrast, systemic 6-OHDA sympathectomised the affected limbs and reduced disease severity.

In summary, noradrenergic postganglionic sympathetic nerves in the joint may have pro-inflammatory actions but it is unclear whether any of this is attributable to the actions of (cholinergic) preganglionic sympathetic nerves (Figure 1). The data suggest that those pro-inflammatory actions are local to the affected joints. A systemic antiinflammatory action of sympathetic nerves to internal organs such as the spleen is more likely to be driven by preganglionic sympathetic neurons $[28,30]$, though this has yet to be tested in the context of arthritis.

\section{Non-neural cholinergic pathways, endotoxemia and macrophages}

Among the proinflammatory cytokines, TNF appears to play a pivotal role in lethal endotoxemia [63]. As indicated 
above, regulation of its levels in rodents by vagus nerve stimulation or dissection in experimental endotoxemia was pivotal early evidence linking the cholinergic pathway to inflammation [6]. Furthermore, nicotine or choline suppressed systemic splenic TNF production in endotoxemic mice, the effect of choline being abolished in $\alpha 7 \mathrm{nAChR}$ knock-out mice $[14,64]$.

Since monocytes/macrophages would appear to be a major source of TNF in response to endotoxin, a number of in vitro studies have been carried out to test the effects of cholinergic agonists on cytokine production in stimulated monocytes/macrophages. It has been reported that in stimulated human monocyte-derived macrophages acetylcholine, choline, nicotine and other agonists inhibited pro-inflammatory cytokine release through an $\alpha 7 \mathrm{nAChR}$ dependent mechanism [6,64-68] - these data for TNF formation are compiled in Table 1. Similar TNF data were found in human monocytes [69,70], mononuclear cells [65] and whole blood [64,71], although the nicotine data could not be confirmed for the monocytes and whole blood [72] (Table 1).

Table 1 Effect of cholinergic agonists on tumour necrosis factor formation in stimulated monocytes/macrophages

\begin{tabular}{|c|c|c|c|}
\hline Cell type & Agonist & TNF levels & Reference \\
\hline \multicolumn{4}{|l|}{ Human } \\
\hline \multirow{3}{*}{$\begin{array}{l}\text { Monocyte-derived } \\
\text { macrophages }\end{array}$} & Acetylcholine, nicotine & $\downarrow$ & [6] \\
\hline & Choline & $\downarrow$ & {$[64]$} \\
\hline & Nicotine & $\downarrow$ & {$[66]$} \\
\hline \multirow[t]{5}{*}{ Monocytes } & Nicotine & $\downarrow$ & {$[70]$} \\
\hline & Nicotine, cotinine & $\downarrow$ & {$[69]$} \\
\hline & Nicotine & $x$ & {$[72]$} \\
\hline & GTS-21 & $\downarrow$ & \\
\hline & Nicotine & $\downarrow$ & {$[65]$} \\
\hline \multirow{3}{*}{$\begin{array}{l}\text { (mononuclear cells) } \\
\text { Whole blood }\end{array}$} & Choline & $\downarrow$ & {$[64]$} \\
\hline & Nicotine & $x$ & {$[72]$} \\
\hline & GTS-21 & $\downarrow$ & \\
\hline (rheumatoid arthritis) & Nicotine, GTS-21 & $\downarrow$ & {$[71]$} \\
\hline \multicolumn{4}{|l|}{ Murine } \\
\hline \multirow{4}{*}{$\begin{array}{l}\text { Resident peritoneal } \\
\text { macrophages }\end{array}$} & Nicotine & $\downarrow$ & {$[13]$} \\
\hline & Nicotine, AR-R17779 & $\downarrow$ & {$[74]$} \\
\hline & Nicotine & $\downarrow$ & {$[73]$} \\
\hline & GTS-21 & $\downarrow$ & {$[84]$} \\
\hline \multirow{4}{*}{$\begin{array}{l}\text { Elicited peritoneal } \\
\text { macrophages }\end{array}$} & Nicotine, acetylcholine & $\downarrow$ & {$[17]$} \\
\hline & Choline & $\downarrow$ & [64] \\
\hline & Acetylcholine & $\downarrow$ & [75] \\
\hline & Nicotine & $\downarrow$ & [76] \\
\hline
\end{tabular}

$\mathrm{X}=$ No change. $\mathrm{TNF}$, tumour necrosis factor.
Both stimulated resident and elicited murine peritoneal macrophages also gave positive findings for suppression of cytokine secretion by the same cholinergic agonists [13,17,73-76] via a proposed Jak2/STAT3 mechanism [13]. However, the more specific $\alpha 7 \mathrm{nAChR}$ agonist, ARR17779, was strangely less potent than nicotine, implying that nicotinic inhibition of macrophage activation may involve other receptors in addition to $\alpha 7 \mathrm{nAChR}[74,75]$; this is consistent with findings that macrophages express several subtypes of nAChR [77]. These data for TNF formation by murine macrophages are also listed in Table 1 . There are obviously some literature data that need to be reconciled.

\section{Non-neural cholinergic signalling in arthritis}

Inflammatory cytokine production in RA whole blood cultures was suppressed by cholinergic agonists [71]. $\alpha 7 \mathrm{nAChR}$ is expressed in the RA synovium, mainly by intimal lining synoviocytes [78]; it is also found in fibroblastlike synoviocytes in vitro [78] and its stimulation in these cells led to potent inhibition of proinflammatory cytokine formation [79]. RA and osteoarthritis synovial biopsies had choline acetyltransferase expression in both the fibroblast-like synoviocytes and mononuclear cells, and it has been suggested that local acetylcholine production (Figure 1) could be contributing to the regulation of joint inflammation by the 'cholinergic anti-inflammatory pathway' [80].

As noted above, it has been reported that the less specific $\alpha 7 \mathrm{nAChR}$ agonist, nicotine, and the more specific agonist, AR-R17779, ameliorated and/or delayed murine collagen-induced arthritis $[48,49]$. In addition, this arthritis in $\alpha 7 \mathrm{nAChR}-/-$ mice was more severe and associated with increased proinflammatory cytokine formation [50]. However, contradictory data in these knock-out mice have been presented in the same model [81]. Nicotine pre-treatment aggravated adjuvant arthritis in rats whereas post-treatment suppressed the disease [82]. In our hands, however, both nicotine and AR-R17779, at concentrations similar to those in [48], failed to suppress murine collagen-induced arthritis (Figure 2). Such divergent observations again remain to be reconciled. What might help is a thorough analysis of the expression of the different nicotine-binding receptors in various arthritis models.

\section{Conclusion}

It is clear that centrally acting muscarinic agonists, electrical stimulation of the vagus to activate preganglionic parasympathetic nerves, and treatment with nAChR agonists can all act systemically (though not necessarily identically) to reduce the production of inflammatory cytokines presumably mostly by macrophages. The full pathways by which they work are complex and 

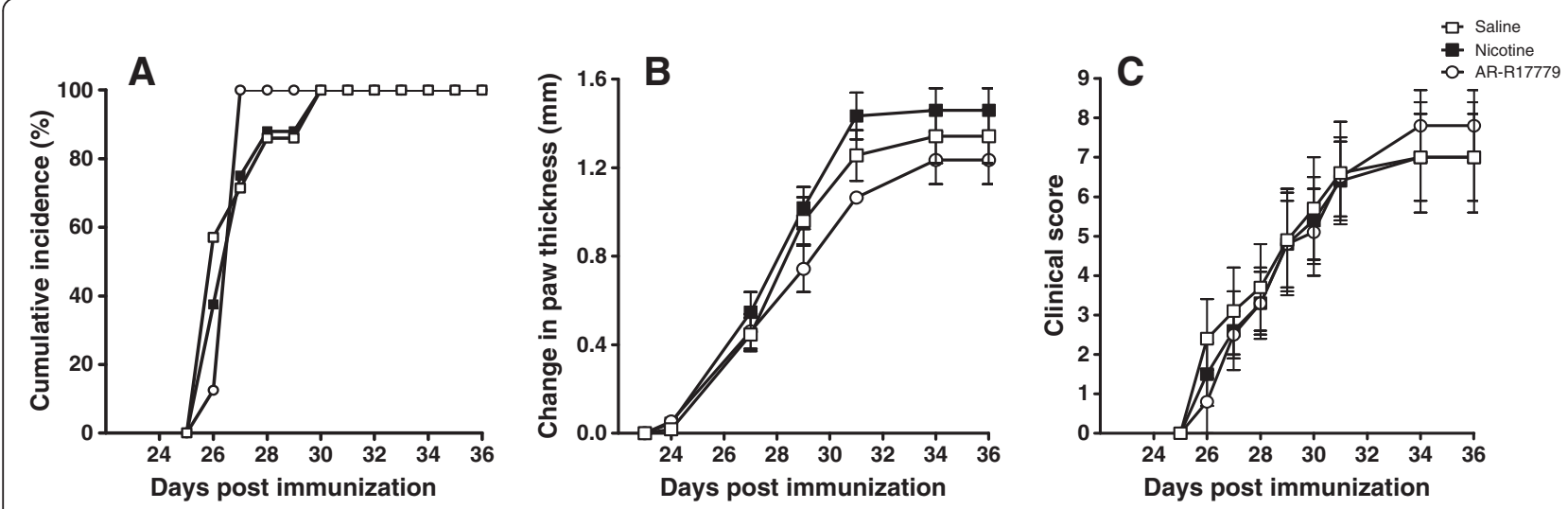

Figure 2 Nicotine and AR-R17779 fail to ameliorate collagen-induced arthritis (CIA). Male DBA/1 mice (6 to 8 weeks) were immunized for CIA on day $0(100 \mu \mathrm{g}$ chick type II collagen in complete Freund's adjuvant containing $5 \mathrm{mg} / \mathrm{ml}$ of heat-killed Mycobacterium tuberculosis), followed by a booster injection on day 21 [85]. Beginning on day 21, mice were treated intraperitoneally with nicotine (400 $\mu \mathrm{g} / \mathrm{kg}), \mathrm{AR}-\mathrm{R} 17779$ (5 mg/kg) or vehicle (saline), twice daily for 7 days. (A) Cumulative incidence (percentage). (B) Change in paw thickness (calliper). (C) Clinical score (0 to 4 per paw; maximum score of 16 per mouse). Data are expressed as mean \pm standard error of the mean; $n=8$ mice per group.

incompletely understood. Systemic treatment with nicotinic agonists has been reported to reduce the incidence and severity of murine arthritis, although we did not confirm this finding. Sympathetic preganglionic neurons also have systemic anti-inflammatory actions that suppress the production of inflammatory cytokines. A key difference is that the sympathetic pathway is activated reflexively by peripheral inflammation while the vagal pathway appears not to be. The actions of sympathetic preganglionic neurons on arthritis may be more complex, however, and need to be clarified.

It is important that further studies are carried out in this area since clinical trials based upon the concept of the 'cholinergic anti-inflammatory pathway' have been proposed and/or are underway [83]. At present, targeting sympathetic or adrenergic processes with drugs is less attractive because their actions may be helpful or unhelpful, depending on the disease stage [60]. Also, the conflict between the actions of local versus systemic sympathetic nerves needs to be untangled for future progress along this line.

Much less convincing in our view is the idea that deficient control by the 'cholinergic ant-inflammatory pathway' is a significant factor leading to the onset or exacerbation of arthritis [47]. The evidence so far indicates that there is no ongoing tone in the vagal 'cholinergic anti-inflammatory pathway' and that it is not the efferent arm of the inflammatory reflex: sympathetic pathways play that role $[28,30]$. The loss of cardiac vagal tone in RA and other inflammatory conditions is a predictable consequence of peripheral inflammation rather than a cause. Until there is convincing evidence to the contrary, we suggest that it could mislead us if we uncritically embrace the 'cholinergic anti-inflammatory pathway' as a significant factor in the pathogenesis of RA.

Note: This article is part of the series 'At the interface between immunology and neurology in rheumatic diseases', edited by Rainer Straub. Other articles in this series can be found at http://arthritisresearch.com/series/neurology

\section{Abbreviations}

6-OHDA: 6-hydroxydopamine; HF-HRV: High frequency heart rate variability; LPS: Lipopolysaccharide; nAChR: nicotinic acetylcholine receptor; RA: Rheumatoid arthritis; TNF: Tumour necrosis factor.

\section{Competing interests}

The authors declare that they have no competing interests.

\section{Acknowledgements}

Work in the authors' laboratories was supported by project grants and research fellowships to RMM and JAH from the National Health and Medical Research Council (NHMRC) of Australia and by the Victorian Government Operational Infrastructure Support Program. HWK was supported by Endeavour IPRS and an Australian Postgraduate Award.

\section{Author details}

${ }^{1}$ Florey Institute of Neuroscience and Mental Health, University of Melbourne, Parkville, Victoria 3010, Australia. ${ }^{2}$ Department of Medicine, Royal Melbourne Hospital, University of Melbourne, Parkville, Victoria 3010, Australia.

Published online: 31 March 2015

\section{References}

1. Veale $D$, Farrell $M$, Fitzgerald $O$. Mechanism of joint sparing in a patient with unilateral psoriatic arthritis and a longstanding hemiplegia. Br J Rheumatol. 1993:32:413-6.

2. Flierl MA, Rittirsch D, Nadeau BA, Chen AJ, Sarma JV, Zetoune FS, et al. Phagocyte-derived catecholamines enhance acute inflammatory injury. Nature. 2007;449:721-5. 
3. Rosas-Ballina M, Olofsson PS, Ochani M, Valdés-Ferrer SI, Levine YA, Reardon $C$, et al. Acetylcholine-synthesizing T cells relay neural signals in a vagus nerve circuit. Science. 2011;334:98-101.

4. Jänig W. The Integrative Action of the Autonomic Nervous System. Cambridge: Cambridge University Press; 2006.

5. Borovikova LV, Ivanova S, Nardi D, Zhang M, Yang H, Ombrellino $M$, et al. Role of vagus nerve signaling in CNI-1493-mediated suppression of acute inflammation. Auton Neurosci. 2000;85:141-7.

6. Borovikova LV, Ivanova S, Zhang M, Yang H, Botchkina Gl, Watkins LR, et al. Vagus nerve stimulation attenuates the systemic inflammatory response to endotoxin. Nature. 2000;405:458-62.

7. Tracey KJ. The inflammatory reflex. Nature. 2002;420:853-9.

8. Pavlov VA, Ochani M, Gallowitsch-Puerta M, Ochani K, Huston JM, Czura CJ, et al. Central muscarinic cholinergic regulation of the systemic inflammatory response during endotoxemia. Proc Natl Acad Sci U S A. 2006;103:5219-23.

9. Pavlov VA, Parrish WR, Rosas-Ballina M, Ochani M, Puerta M, Ochani K, et al Brain acetylcholinesterase activity controls systemic cytokine levels through the cholinergic anti-inflammatory pathway. Brain Behav Immun. 2009;23:41-5.

10. Langley RJ, Kalra R, Mishra NC, Sopori ML. Central but not the peripheral action of cholinergic compounds suppresses the immune system. J Neuroimmunol. 2004;148:140-5.

11. Yoon SY, Kwon YB, Kim HW, Roh DH, Seo HS, Han HJ, et al. A spinal muscarinic M2 receptor-GABAergic disinhibition pathway that modulates peripheral inflammation in mice. Neuropharmacology. 2007:53:677-86.

12. Yoon SY, Kim HW, Roh DH, Kwon YB, Jeong TO, Han HJ, et al. The anti-inflammatory effect of peripheral bee venom stimulation is mediated by central muscarinic type 2 receptors and activation of sympathetic preganglionic neurons. Brain Res. 2005:1049:210-6.

13. de Jonge WJ, van der Zanden EP, The FO, Bijlsma MF, van Westerloo DJ, Bennink RJ, et al. Stimulation of the vagus nerve attenuates macrophage activation by activating the Jak2-STAT3 signaling pathway. Nat Immunol 2005;6:844-51

14. Rosas-Ballina M, Ochani M, Parrish WR, Ochani K, Harris YT, Huston JM, et al. Splenic nerve is required for cholinergic antiinflammatory pathway control of TNF in endotoxemia. Proc Natl Acad Sci U S A. 2008;105:11008-13.

15. Andersson U, Tracey KJ. Reflex principles of immunological homeostasis. Annu Rev Immunol. 2012;30:313-35.

16. Vida G, Peña G, Kanashiro A, Thompson-Bonilla Mdel R, Palange D, Deitch $E A$, et al. beta2-Adrenoreceptors of regulatory lymphocytes are essential for vagal neuromodulation of the innate immune system. FASEB J. 2011:25:4476-85.

17. Wang H, Yu M, Ochani M, Amella CA, Tanovic M, Susarla S, et al. Nicotinic acetylcholine receptor alpha7 subunit is an essential regulator of inflammation. Nature. 2003:421:384-8.

18. Martelli D, McKinley MJ, McAllen RM. The cholinergic anti-inflammatory pathway: a critical review. Auton Neurosci. 2014;182:65-9.

19. de Jonge WJ, Ulloa $L$. The alpha7 nicotinic acetylcholine receptor as a pharmacological target for inflammation. Br J Pharmacol. 2007;151:915-29.

20. Huston JM, Ochani M, Rosas-Ballina M, Liao H, Ochani K, Pavlov VA, et al. Splenectomy inactivates the cholinergic antiinflammatory pathway during lethal endotoxemia and polymicrobial sepsis. J Exp Med. 2006:203:1623-8.

21. Bratton BO, Martelli D, McKinley MJ, Trevaks D, Anderson CR, McAllen RM. Neural regulation of inflammation: no neural connection from the vagus to splenic sympathetic neurons. Exp Physiol. 2012;97:1180-5.

22. Reardon C, Duncan GS, Brüstle A, Brenner D, Tusche MW, Olofsson PS, et al. Lymphocyte-derived $A C h$ regulates local innate but not adaptive immunity. Proc Natl Acad Sci U S A. 2013;110:1410-5.

23. Saeed RW, Varma S, Peng-Nemeroff T, Sherry B, Balakhaneh D, Huston J, et al. Cholinergic stimulation blocks endothelial cell activation and leukocyte recruitment during inflammation. J Exp Med. 2005;201:1113-23.

24. Besedovsky H, del Rey A, Sorkin E, Dinarello CA. Immunoregulatory feedback between interleukin-1 and glucocorticoid hormones. Science. 1986;233:652-4.

25. Turrin NP, Rivest S. Unraveling the molecular details involved in the intimate link between the immune and neuroendocrine systems. Exp Biol Med (Maywood). 2004:229:996-1006.

26. Bernik TR, Friedman SG, Ochani M, DiRaimo R, Ulloa L, Yang H, et al. Pharmacological stimulation of the cholinergic antiinflammatory pathway. J Exp Med. 2002;195:781-8.
27. Fuentes JM, Hanly EJ, Aurora AR, De Maio A, Talamini MA. Anesthesia-specific protection from endotoxic shock is not mediated through the vagus nerve. Surgery. 2005;138:766-71.

28. Martelli D, Yao ST, McKinley MJ, McAllen RM. Reflex control of inflammation by sympathetic nerves, not the vagus. J Physiol. 2014;592:1677-86.

29. Mihaylova S, Killian A, Mayer K, Pullamsetti SS, Schermuly R, Rosengarten B. Effects of anti-inflammatory vagus nerve stimulation on the cerebral microcirculation in endotoxinemic rats. J Neuroinflammation. 2012;9:183.

30. Elenkov IJ, Wilder RL, Chrousos GP, Vizi ES. The sympathetic nerve - an integrative interface between two supersystems: the brain and the immune system. Pharmacol Rev. 2000;52:595-638.

31. Kenney MJ, Ganta CK. Autonomic nervous system and immune system interactions. Compr Physiol. 2014;4:1177-200.

32. Nance DM, Sanders VM. Autonomic innervation and regulation of the immune system (1987-2007). Brain Behav Immun. 2007;21:736-45.

33. van Westerloo DJ, Giebelen IA, Florquin S, Daalhuisen J, Bruno MJ, de Vos $A F$, et al. The cholinergic anti-inflammatory pathway regulates the host response during septic peritonitis. J Infect Dis. 2005;191:2138-48.

34. van Westerloo DJ, Giebelen IA, Florquin S, Bruno MJ, Larosa GJ, Ulloa L, et al. The vagus nerve and nicotinic receptors modulate experimental pancreatitis severity in mice. Gastroenterology. 2006;130:1822-30.

35. Van Der Zanden EP, Boeckxstaens GE, de Jonge WJ. The vagus nerve as a modulator of intestinal inflammation. Neurogastroenterol Motil. 2009;21:6-17.

36. McQueen DS, Donaldson K, Bond SM, McNeilly JD, Newman S, Barton NJ, et al. Bilateral vagotomy or atropine pre-treatment reduces experimental diesel-soot induced lung inflammation. Toxicol Appl Pharmacol. 2007;219:62-71.

37. Agostoni E, Chinnock JE, de Daly MB, Murray JG. Functional and histological studies of the vagus nerve and its branches to the heart, lungs and abdominal viscera in the cat. J Physiol. 1957;135:182-205.

38. Ghia JE, Blennerhassett P, Collins SM. Vagus nerve integrity and experimental colitis. Am J Physiol Gastrointest Liver Physiol. 2007;293:G560-7.

39. Handwerker HO, Holzer-Petscher U, Heym C, Welk E. C-fibre functions after topical applicatio of capsaicin to a peripheral nerve and after neonatal capsaicin treatment. In: Chahl LA, Szolcsanyi J, Lembeck F, editors. Antidromic vasodilatation and neurogenic inflammation. Budapest: Akademiai Kiado; 1984. p. 57-78.

40. Mazelin L, Theodorou V, More J, Fioramonti J, Bueno L. Protective role of vagal afferents in experimentally-induced colitis in rats. J Auton Nerv Syst. 1998;73:38-45

41. McCafferty DM, Wallace $J$, Sharkey KA. Effects of chemical sympathectomy and sensory nerve ablation on experimental colitis in the rat. Am J Physiol. 1997;272:G272-80

42. Luyer MD, Greve JW, Hadfoune M, Jacobs JA, Dejong CH, Buurman WA. Nutritional stimulation of cholecystokinin receptors inhibits inflammation via the vagus nerve. J Exp Med. 2005:202:1023-9.

43. Luyer MD, Buurman WA, Hadfoune M, Jacobs JA, Konstantinov SR, Dejong $\mathrm{CH}$, et al. Pretreatment with high-fat enteral nutrition reduces endotoxin and tumor necrosis factor-alpha and preserves gut barrier function early after hemorrhagic shock. Shock. 2004;21:65-71.

44. Raybould HE. Mechanisms of CCK signaling from gut to brain. Curr Opin Pharmacol. 2007;7:570-4.

45. de Haan JJ, Windsant IV, Lubbers T, Hanssen SJ, Hadfoune M, Prinzen FW, et al. Prevention of hemolysis-induced organ damage by nutritional activation of the vagal anti-inflammatory reflex. Crit Care Med. 2013;41:e361-7.

46. de Jonge WJ, van den Wijngaard RM, The FO, ter Beek ML, Bennink RJ, Tytgat GN, et al. Postoperative ileus is maintained by intestinal immune infiltrates that activate inhibitory neural pathways in mice. Gastroenterology. 2003;125:1137-47.

47. Goldstein RS, Bruchfeld A, Yang L, Qureshi AR, Gallowitsch-Puerta M, Patel NB, et al. Cholinergic anti-inflammatory pathway activity and High Mobility Group Box-1 (HMGB1) serum levels in patients with rheumatoid arthritis. Mol Med. 2007;13:210-5.

48. van Maanen MA, Lebre MC, van der Poll T, LaRosa GJ, Elbaum D, Vervoordeldonk MJ, et al. Stimulation of nicotinic acetylcholine receptors attenuates collagen-induced arthritis in mice. Arthritis Rheum. 2009:60:114-22

49. Wu S, Luo H, Xiao X, Zhang H, Li T, Zuo X. Attenuation of collagen induced arthritis via suppression on Th17 response by activating cholinergic anti-inflammatory pathway with nicotine. Eur J Pharmacol. 2014;735:97-104. 
50. van Maanen MA, Stoof SP, Larosa GJ, Vervoordeldonk MJ, Tak PP. Role of the cholinergic nervous system in rheumatoid arthritis: aggravation of arthritis in nicotinic acetylcholine receptor alpha7 subunit gene knockout mice. Ann Rheum Dis. 2010;69:1717-23.

51. Carlens C, Brandt L, Klareskog L, Lampa J, Askling J. The inflammatory reflex and risk for rheumatoid arthritis: a case-control study of human vagotomy. Ann Rheum Dis. 2007;66:414-6.

52. Stojanovich L, Milovanovich B, de Luka SR, Popovich-Kuzmanovich D, Bisenich V, Djukanovich B. Cardiovascular autonomic dysfunction in systemic lupus, rheumatoid arthritis, primary Sjogren syndrome and other autoimmune diseases. Lupus. 2007;16:181-5.

53. Kon H, Nagano M, Tanaka F, Satoh K, Segawa T, Nakamura M. Association of decreased variation of $\mathrm{R}-\mathrm{R}$ interval and elevated serum C-reactive protein level in a general population in Japan. Int Heart J. 2006;47:867-76.

54. Godin PJ, Fleisher LA, Eidsath A, Vandivier RW, Preas HL, Banks SM, et al. Experimental human endotoxemia increases cardiac regularity: results from a prospective, randomized, crossover trial. Crit Care Med. 1996;24:1117-24.

55. Saper CB, Romanovsky AA, Scammell TE. Neural circuitry engaged by prostaglandins during the sickness syndrome. Nat Neurosci. 2012;15:1088-95

56. Zhang P, Han D, Tang T, Zhang X, Dai K. Inhibition of the development of collagen-induced arthritis in Wistar rats through vagus nerve suspension: a 3-month observation. Inflamm Res. 2008:57:322-8.

57. Levine YA, Koopman FA, Faltys M, Caravaca A, Bendele A, Zitnik R, et al. Neurostimulation of the cholinergic anti-inflammatory pathway ameliorates disease in rat collagen-induced arthritis. PLoS One. 2014;9:e104530

58. Janig W, Green PG. Acute inflammation in the joint: its control by the sympathetic nervous system and by neuroendocrine systems. Auton Neurosci. 2014;182:42-54

59. Capellino S, Weber K, Gelder M, Härle P, Straub RH. First appearance and location of catecholaminergic cells during experimental arthritis and elimination by chemical sympathectomy. Arthritis Rheum. 2012;64:1110-8.

60. Härle P, Möbius D, Carr DJ, Schölmerich J, Straub RH. An opposing time-dependent immune-modulating effect of the sympathetic nervous system conferred by altering the cytokine profile in the local lymph nodes and spleen of mice with type II collagen-induced arthritis. Arthritis Rheum. 2005;52:1305-13.

61. Lorton D, Lubahn C, Klein N, Schaller J, Bellinger DL. Dual role for noradrenergic innervation of lymphoid tissue and arthritic joints in adjuvant-induced arthritis. Brain Behav Immun. 1999;13:315-34.

62. Lorton D, Bellinger D, Duclos M, Felten SY, Felten DL. Application of 6-hydroxydopamine into the fatpads surrounding the draining lymph nodes exacerbates adjuvant-induced arthritis. J Neuroimmunol. 1996;64:103-13.

63. Tracey KJ, Vlassara H, Cerami A. Cachectin/tumour necrosis factor. Lancet 1989:1:1122-6

64. Parrish WR, Rosas-Ballina M, Gallowitsch-Puerta M, Ochani M, Ochani K, Yang $\mathrm{LH}$, et al. Modulation of TNF release by choline requires alpha7 subunit nicotinic acetylcholine receptor-mediated signaling. Mol Med. 2008;14:567-74.

65. Hamano R, Takahashi HK, Iwagaki H, Yoshino T, Nishibori M, Tanaka N. Stimulation of alpha7 nicotinic acetylcholine receptor inhibits CD14 and the toll-like receptor 4 expression in human monocytes. Shock. 2006;26:358-64.

66. Joe Y, Kim HJ, Kim S, Chung J, Ko MS, Lee WH, et al. Tristetraprolin mediates anti-inflammatory effects of nicotine in lipopolysaccharide-stimulated macrophages. J Biol Chem. 2011;286:24735-42.

67. Ulloa $L$. The vagus nerve and the nicotinic anti-inflammatory pathway. Nat Rev Drug Discov. 2005;4:673-84.

68. Wang H, Liao H, Ochani M, Justiniani M, Lin X, Yang L, et al. Cholinergic agonists inhibit HMGB1 release and improve survival in experimental sepsis. Nat Med. 2004;10:1216-21.

69. Rehani K, Scott DA, Renaud D, Hamza H, Williams LR, Wang H, et al. Cotinine-induced convergence of the cholinergic and PI3 kinase-dependent anti-inflammatory pathways in innate immune cells. Biochim Biophys Acta. 2008;1783:375-82.

70. Yoshikawa H, Kurokawa M, Ozaki N, Nara K, Atou K, Takada E, et al. Nicotine inhibits the production of proinflammatory mediators in human monocytes by suppression of I-kappaB phosphorylation and nuclear factor-kappaB transcriptional activity through nicotinic acetylcholine receptor alpha7. Clin Exp Immunol. 2006;146:116-23

71. Bruchfeld A, Goldstein RS, Chavan S, Patel NB, Rosas-Ballina M, Kohn N, et al. Whole blood cytokine attenuation by cholinergic agonists ex vivo and relationship to vagus nerve activity in rheumatoid arthritis. J Intern Med. 2010:268:94-101.

72. Rosas-Ballina M, Goldstein RS, Gallowitsch-Puerta M, Yang L, Valdés-Ferrer SI, Patel NB, et al. The selective alpha7 agonist GTS-21 attenuates cytokine production in human whole blood and human monocytes activated by ligands for TLR2, TLR3, TLR4, TLR9, and RAGE. Mol Med. 2009;15:195-202.

73. Li J, Mathieu SL, Harris R, Ji J, Anderson DJ, Malysz J, et al. Role of alpha7 nicotinic acetylcholine receptors in regulating tumor necrosis factor-alpha (TNF-alpha) as revealed by subtype selective agonists. J Neuroimmunol. 2011;239:37-43.

74. The FO, Boeckxstaens GE, Snoek SA, Cash JL, Bennink R, Larosa GJ, et al. Activation of the cholinergic anti-inflammatory pathway ameliorates postoperative ileus in mice. Gastroenterology. 2007;133:1219-28.

75. van der Zanden EP, Snoek SA, Heinsbroek SE, Stanisor OI, Verseijden C, Boeckxstaens $G E$, et al. Vagus nerve activity augments intestinal macrophage phagocytosis via nicotinic acetylcholine receptor alpha4beta2. Gastroenterology. 2009;137:1029-39. 1039 e1-4.

76. Wang X, Yang Z, Xue B, Shi H. Activation of the cholinergic antiinflammatory pathway ameliorates obesity-induced inflammation and insulin resistance. Endocrinology. 2011;152:836-46.

77. Kawashima K, Yoshikawa K, Fujii YX, Moriwaki Y, Misawa H. Expression and function of genes encoding cholinergic components in murine immune cells. Life Sci. 2007:80:2314-9.

78. van Maanen MA, Stoof SP, van der Zanden EP, de Jonge WJ, Janssen RA, Fischer DF, et al. The alpha7 nicotinic acetylcholine receptor on fibroblastlike synoviocytes and in synovial tissue from rheumatoid arthritis patients: a possible role for a key neurotransmitter in synovial inflammation. Arthritis Rheum. 2009:60:1272-81.

79. Waldburger JM, Boyle DL, Pavlov VA, Tracey KJ, Firestein GS. Acetylcholine regulation of synoviocyte cytokine expression by the alpha7 nicotinic receptor. Arthritis Rheum. 2008;58:3439-49.

80. Grimsholm O, Rantapää-Dahlqvist S, Dalén T, Forsgren S. Unexpected finding of a marked non-neuronal cholinergic system in human knee joint synovial tissue. Neurosci Lett. 2008;442:128-33.

81. Westman M, Saha S, Morshed M, Lampa J. Lack of acetylcholine nicotine alpha 7 receptor suppresses development of collagen-induced arthritis and adaptive immunity. Clin Exp Immunol. 2010;162:62-7.

82. Yu H, Yang YH, Rajaiah R, Moudgil KD. Nicotine-induced differential modulation of autoimmune arthritis in the Lewis rat involves changes in interleukin-17 and anti-cyclic citrullinated peptide antibodies. Arthritis Rheum. 2011;63:981-91.

83. Koopman FA, Schuurman PR, Vervoordeldonk MJ, Tak PP. Vagus nerve stimulation: a new bioelectronics approach to treat rheumatoid arthritis? Best Pract Res Clin Rheumatol. 2014:28:625-35.

84. Khan MA, Farkhondeh M, Crombie J, Jacobson L, Kaneki M, Martyn JA. Lipopolysaccharide upregulates alpha7 acetylcholine receptors: stimulation with GTS-21 mitigates growth arrest of macrophages and improves survival in burned mice. Shock. 2012:38:213-9.

85. Cook AD, Braine EL, Campbell IK, Rich MJ, Hamilton JA. Blockade of collagen-induced arthritis post-onset by antibody to granulocytemacrophage colony-stimulating factor (GM-CSF): requirement for GM-CSF in the effector phase of disease. Arthritis Res. 2001;3:293-8. 